\title{
Carbapenemase-producing Enterobacteriaceae in Mexico: report of seven non-clonal cases in a pediatric hospital
}

\author{
Alejandra Aquino-Andrade ${ }^{1}$, Jocelin Merida-Vieyra', Eduardo Arias de la Garza², Patricia Arzate-Barbosa ${ }^{3}$
} and Agustín De Colsa Ranero ${ }^{1,2^{*}}$

\begin{abstract}
Background: Carbapenemases-producing Enterobacteriaceae (CPE) are a worldwide public health emergency. In Mexico, reports of CPE are limited, particularly in the pediatric population. Here, we describe the clinical, epidemiological, and molecular characteristics of seven consecutive cases in a third-level pediatric hospital in Mexico City over a four-month period during 2016.

Results: The Enterobacteriaceae identified were three Escherichia coli strains (producing OXA-232, NDM-1 and KPC-2), two Klebsiella pneumoniae strains (producing KPC-2 and NDM-1), one Klebsiella oxytoca strain producing OXA-48 and one Enterobacter cloacae strain producing NDM-1. The majority of patients had underlying disesases, three were immunocompromised, and three had infections involved the skin and soft tissues. Half patients died as a result of CPE infection.

Conclusions: This study represents the first report of E. coli ST131-O25b clone producing NDM-1 in Latin America. In addition, this study is the first finding of K. oxytoca producing OXA-48 and E. coli producing OXA-232 in Mexican pediatric patients.
\end{abstract}

Keywords: Carbapenemase-producing Enterobacteriaceae, Pediatrics, Mexico, NDM-1, KPC-2, OXA-48, OXA-232

\section{Background}

Currently, antimicrobial resistance is considered a global public health problem of highest priority, and the emergence of CPE is increasing. This situation is especially alarming due to the ease of dispersion of these resistance mechanisms, the difficulty in choosing adequate antimicrobial therapy, and the increase in mortality and hospital stay lengths caused by infections with these pathogens [1]. The mortality of patients infected with CPE varies from $26 \%$ to $44 \%$ [2] and can reach as high as $85 \%$ in patients with CPE bloodstream infections [3].

\footnotetext{
* Correspondence: agustin.decolsa@infecto.mx

${ }^{1}$ Molecular Microbiology Laboratory, Instituto Nacional de Pediatría, Insurgentes Sur 3700-C, Insurgentes Cuicuilco, ZC, 04530 Coyoacán Mexico City, Mexico

${ }^{2}$ Pediatric Infectious Disease Department, Instituto Nacional de Pediatria, Mexico City, Mexico

Full list of author information is available at the end of the article
}

Carbapenem resistance in Enterobacteriaceae is largely mediated by the presence of enzymes known as carbapenemases, which have the capacity to inactivate betalactam antibiotics, including third- and fourth-generation cephalosporins and carbapenems. The most common carbapenemases in Enterobacteriaceae are the VIM, IMP, KPC, NDM and OXA types [4].

The frequency of CPE isolation varies among regions of the world. In the U.S., the CPE frequency from 1999 to 2012 was $0.08 \%$, and species of Enterobacter were the most common isolates (0.57\%) [5]. The Antimicrobial Surveillance Program SENTRY, carried out in 18 European countries from 2010 to 2013, evaluated 14,286 Enterobacteriaceae isolates and found that 2\% were CPE, with a frequency varying from $0.1 \%$ (Ireland) to $17.3 \%$ (Poland). The most common CPE species were $K$. pneumoniae (86.4\%) and E. cloacae (7.9\%), and the most 
frequent carbapenemases found in this study were KPC 2/3 (85.4\%), VIM (12.5\%), and IMP-19 (2.1\%) [6]. The equivalent program in Latin America, which included 11 countries during 2011-2014, revealed that $4.3 \%$ of isolates of Enterobacteriaceae were $\mathrm{CPE}$, with the highest frequencies reported in Brazil (9\%) and Argentina (6.3\%). In Mexico, the reported frequencies of CPE were $0.7 \%$ [7].

In the National Institute of Pediatrics (INP) we performed a retrospective analysis of Enterobacteriaceae isolates collected during February 2013-January 2015, based on antimicrobial susceptibility testing and molecular tests, and we only identified four E. cloacae isolates producing VIM-2.

In April 2016, the Pediatric Infectious Diseases Department detected a CPE in a patient with sepsis and neutropenic colitis. In the next months, six additional CPE were reported in the INP.

In this study, we describe the clinical, epidemiological and molecular data from a series of consecutive infection cases caused by seven CPE during a four-month period.

\section{Methods}

\section{Study site}

The INP is a public teaching-hospital with 243 beds, and is one of the largest pediatric reference centers in Mexico.

\section{Clinical aspects}

Over a four-month period (April-July 2016), seven nonclonal Enterobacteriaceae isolates causing different clinical infections were obtained. The resistance profiles of these bacteria suggested that they were carbapenemases producers.

We reviewed the medical file from each patient to collect clinical and epidemiological data such as: demographic characteristics, underlying medical condition, previous antibiotic treatment, surgical procedure, mechanical ventilation, stay in pediatric intensive care unit (PICU), and number of clinical departments during hospitalization, among others. Acquisition of the different infections was determined to be healthcare-associated infections according to the definitions of the Centers for Disease Control and Prevention [8]. For this study, a case was defined as the appearance of at least one infection by a CPE that was clinically and microbiologically documented.

\section{Microbiological methods}

The identification and susceptibility profiles of the isolates were performed using the Phoenix ${ }^{\circ}$ BD system (Becton Dickinson, Sparks, MD, U.S.). The production of extended spectrum beta-lactamases (ESBL) and carbapenemases was confirmed phenotypically using the combined disk method and the CarbaNP test, respectively. We determined the minimum inhibitory concentration to colistin according to the Clinical Laboratory Standards Institute (CLSI) [9].

\section{Beta-lactamase typing}

We extracted DNA from each isolate using the QIAamp ${ }^{\circ}$ DNA Mini kit (QIAGEN, Hilden, Germany). We detected beta-lactamases by PCR amplification of bla $a_{\mathrm{CTX}-\mathrm{M}-1 \text {, }}$ $b l a_{\mathrm{CTX}-\mathrm{M}-2,}, b l a_{\mathrm{CTX}-\mathrm{M}-9}, b l a_{\mathrm{SHV}}, b l a_{\mathrm{TEM}}, b l a_{\mathrm{LAT}}, b l a_{\mathrm{DHA}}$, $b l a_{\mathrm{VIM}}, b l a_{\mathrm{IMP}} b l a_{\mathrm{NDM}}, b l a_{\mathrm{KPC}}$ and $b l a_{\mathrm{OXA}-48}$ genes using a GenAmp PCR System 9700 thermal cycler (Applied Biosystems Foster City, CA, USA). AmpliTaq Gold ${ }^{\circ} 360$ MasterMix (Applied Biosystems) was used for all reactions; the primers and amplification conditions were described previously [10-12]. The amplified fragments were purified using the QIAquick PCR purification kit (QIAGEN), and each product obtained was sequenced using a $3500 \mathrm{XL}$ System (Applied Biosystems). We determined the beta-lactamase subtype using the BLAST bioinformatic tool.

\section{Multilocus sequence typing}

Multilocus sequence typing (MLST) was performed on the E. coli, $K$. pneumoniae, and E. cloacae isolates [13-15]. We amplified $\operatorname{trp} A, p a b B$ and $r f b$ genes using conditions previously described, to detect the O25b-ST131 clone for all E. coli isolates [16].

\section{Results}

\section{Bacterial isolates and detection of beta-lactamases}

We identified three strains of E. coli, two of K. pneumoniae, one of Klebsiella oxytoca, and one of E. cloacae. All isolates were carbapenem resistant but showed differences in their susceptibility profiles to other antibiotic families, no resistance to colistin was observed in any isolate (Table 1). The confirmatory test for ESBL detection was positive for two isolates ( $\mathrm{C} 1$ and $\mathrm{C} 2)$. Coexistence of other beta-lactamases, including TEM-1, SHV-1 (non-ESBL), SHV-12, and CTX-M-15 (ESBL), was found in five isolates, two isolates with CTX-M-15 and NDM-1 were negative for ESBL test (Table 2). None isolate possessed genes encoding enzymes of the CTX-M-2, CTX-M-9, DHA, or LAT type.

\section{Phenotypic tests, carbapenemases detection and MLST}

Five isolates were positive for the CarbaNP test. However, carbapenemase production was not detected using this technique in isolates producing OXA-type enzymes. Four carbapenemase types were detected: NDM1, KPC-2, OXA-48 and OXA-232 in the seven isolates studied (Table 1). The sequence types (ST) of the E. coli isolates were ST2003 (C1), ST457 (C3), and ST131 (C5); 


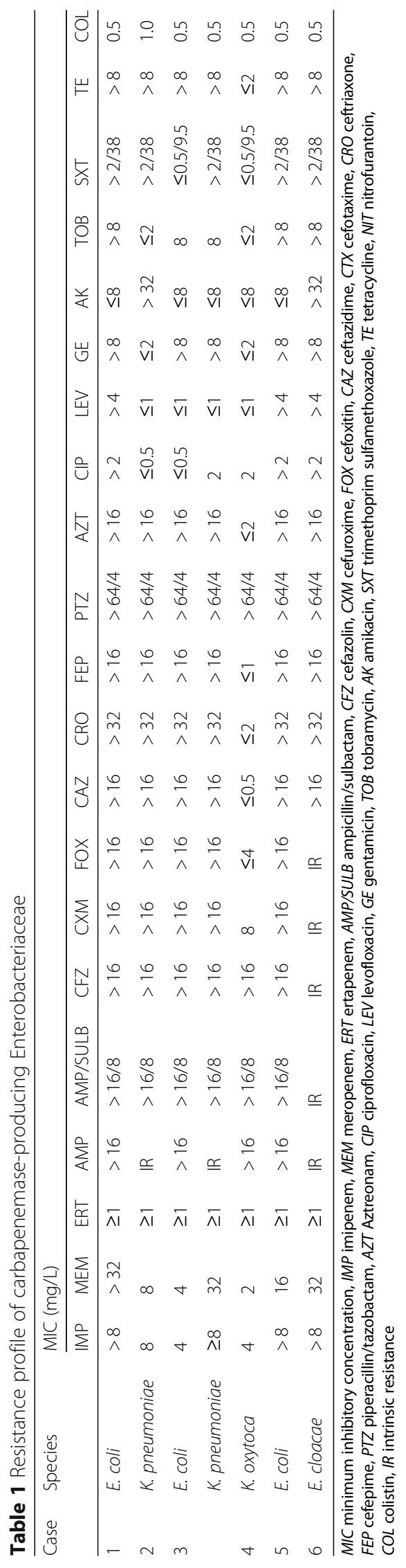


Table 2 Genotype characteristics of carbapenemase-producing Enterobacteriaceae

\begin{tabular}{|c|c|c|c|c|c|c|}
\hline Case & Species & ESBL & Co-existing beta-lactamases & CarbaNP test & CBP & MLST \\
\hline 1 & E. coli & + & CXT-M-15 & - & OXA-232 & ST2003 \\
\hline 2 & K. pneumoniae & + & SHV-12 & + & NDM-1 & ST76 \\
\hline \multirow[t]{2}{*}{3} & E. coli & - & - & + & $\mathrm{KPC}-2$ & ST457 \\
\hline & K. pneumoniae & - & $\mathrm{SHV}-1^{*}$ & + & $\mathrm{KPC}-2$ & ST5 \\
\hline 4 & K. oxytoca & - & - & - & OXA-48 & ND \\
\hline 5 & E. coli & - & CXT-M-15 & + & NDM-1 & ST131-O25b \\
\hline 6 & E. cloacae & - & CXT-M-15, TEM-1 * & + & NDM-1 & ST182 \\
\hline
\end{tabular}

ESBL phenotype test for the detection of extended-spectrum beta-lactamases, CBP carbapenemases, $-:$ negative, $+:$ positive, ${ }^{*}:$ non-ESBL, ND: not determined

K. pneumoniae isolates were ST5 (C3) and ST76 (C2), and E. cloacae ST182 (C6) (Table 2).

\section{Clinical and epidemiological characteristics}

These isolates were obtained from six patients, one of whom had an infection with two isolates (C3), both producing $\mathrm{KPC}-2$. With the exception of one female, all patients were male. The average age was 6.7 years (range 4 months - 16 years). Five patients had an underlying disease and three, were immunocompromised $(\mathrm{C} 1, \mathrm{C} 4$ and $\mathrm{C5}$ ). Three patients presented skin and soft tissue infections (C2, C3 and C6). All deaths occurred in patients who CPE was isolated in blood. All of them had an intra-abdominal source of infection and secondary sepsis (Table 3).

Before sampling for CPE screening, all patients had been hospitalized with an average of 41 days (range 8 to 157 days); therefore, all infections were considered to be healthcare-associated. Only two patients were admitted to an institution other than INP in the 30 days prior to infection ( $\mathrm{C} 2$ and $\mathrm{C} 6)$. Five patients required admission to the pediatric intensive care unit (PICU), mechanical ventilation, and central venous catheter placement, whereas four patients received total parenteral nutrition. Five patients had surgery prior to $\mathrm{CPE}$ isolation (Table 3).

Regarding prior use of antimicrobials, all patients received third or fourth generation cephalosporins, whereas all patients were treated with carbapenems. $\mathrm{CPE}$ were isolated in one patient (C6) while receiving meropenem.

Only two patients ( $\mathrm{C} 1$ and $\mathrm{C6})$ received treatment with colistin days prior to the isolation of CPE (Table 3).

\section{Discussion}

In this report, we describe the consecutive emergence of seven CPE isolates in a third-level pediatric hospital: three E. coli producing NDM-1, KPC-2 and OXA-232, two K. pneumoniae producing KPC-2 and NDM-1, one $K$. oxytoca producing OXA-48, and one E. cloacae producing NDM-1. These pathogens with these carbapenemases appear for the first time in our institution.
Previous to this report, we did not have an active screening to detect colonizing patients. In this study, all infections were considered primary cases. None patient had secondary cases due to the control measures that were taken, such as strictly supervised hand washing, staff training, restriction of personnel in contact with the patients, isolation of the patients in private rooms, exhaustive cleaning and decontamination of physical areas, and alerts on their conditions in the medical records of the discharged patients for future admissions.

Worldwide, K. pneumoniae, E. coli and Enterobacter spp. are the most frequent species of Enterobacteriaceae producing carbapenemases [6, 7]. To date, $K$ oxytoca has rarely been associated with carbapenemase production [17]. In Mexico, $K$. oxytoca has been related to VIM-2 production [18]; in other Latin American countries, production of other carbapenemases, including KPC-2 [19], IMP-4 [20], and VIM-4, have also been reported [21].

Descriptions of CPE with KPC-2 in Mexico are limited. From 2010 to 2014, KPC-2 and KPC-3producing isolates of $K$. pneumoniae were reported $[22,23]$. In one patient, we found two isolates that produce KPC-2, one $K$. pneumoniae strain and another E. coli strain (C3). This study is the first report of KPC-2-producing E. coli in pediatric patients in Mexico; this isolate belongs to ST457. In Australia, E. coli ST457 has been described with CMY-1 and CTX-M-15, isolated from dog feces and extraintestinal infections [24] and in Korea with OXA-232 in healthy individuals colonized [25].

The first report of NDM-1 in Mexico was registered in 2012, and the first cases were associated with an outbreak of a Providencia rettgeri clone [26]. In Mexico, E. coli (ST617), E. cloacae (ST182), and K. pneumoniae (ST22) isolates from adult patients [27] and K. pneumoniae (ST22) isolates from pediatric patients [28] have also been found to produce NDM-1. In the present series, NDM-1 was the enzyme most commonly found. This study is the first report of E. coli (C5) and E. cloacae (C6) producing NDM-1 in pediatric patients in Mexico. 
Table 3 Characteristics of patients with carbapenemase-producing Enterobacteriaceae

\begin{tabular}{|c|c|c|c|c|c|c|}
\hline \multirow[t]{4}{*}{ Data } & \multicolumn{6}{|l|}{ Cases } \\
\hline & 1 & 2 & 3 & 4 & 5 & 6 \\
\hline & E. coli & K. pneumoniae & $\begin{array}{l}\text { E. coli } \\
\text { K. pneumoniae }\end{array}$ & K. oxytoca & E. coli & E. cloacae \\
\hline & OXA-232 & NDM-1 & $\mathrm{KPC}-2$ & OXA-48 & NDM-1 & NDM-1 \\
\hline Base diagnosis & AML-M2 & Intestinal malrotation & KTWS & preB-ALL & $\begin{array}{l}\text { Trisomy } 21, \\
\text { Fallot Tetralogy }\end{array}$ & $\begin{array}{l}\text { Complicated } \\
\text { varicella }\end{array}$ \\
\hline $\begin{array}{l}\text { Immuno- } \\
\text { compromised }\end{array}$ & Yes & No & No & Yes & Yes & No \\
\hline Infection & $\begin{array}{l}\text { Sepsis, Neutropenic } \\
\text { colitis }\end{array}$ & $\begin{array}{l}\text { Necrotizing } \\
\text { fasciitis, SSI }\end{array}$ & Cellulitis, SSI & $\begin{array}{l}\text { Abdominal } \\
\text { sepsis }\end{array}$ & UTI & Necrotizing fasciitis \\
\hline Sample & Blood, peritoneal liquid & $\begin{array}{l}\text { Blood, wound } \\
\text { drainage }\end{array}$ & $\begin{array}{l}\text { Surgical wound } \\
\text { drainage }\end{array}$ & Blood & Urine & Wound drainage \\
\hline ID time ${ }^{a}$ & 10 & 8 & 22 & 39 & 157 & 9 \\
\hline Other hospital & No & Yes & No & No & No & Yes \\
\hline PICU & Yes & Yes & Yes & Yes & Yes & No \\
\hline MV & Yes & Yes & Yes & Yes & Yes & No \\
\hline Surgery & No & Yes & Yes & Yes & Yes & Yes \\
\hline CVC & Yes & Yes & Yes & Yes & Yes & No \\
\hline TPN & No & Yes & Yes & Yes & Yes & No \\
\hline \multicolumn{7}{|l|}{ Previous $A B$} \\
\hline 3GC (days) & No & Yes (2) & Yes (23) & Yes $(3)^{c}$ & Yes (7) & Yes (3) \\
\hline 4CG (days) & Yes (1) & No & No & Yes $(8)^{c}$ & No & No \\
\hline Carbapenems & Yes (8) & Yes (18) & Yes $(42)^{b}$ & Yes $(26)^{b}$ & Yes (37) & Yes $(29)^{b}$ \\
\hline Colistin & No & No & No & No & Yes & No \\
\hline Definitive Tx & COL+MEM & MEM + LEV & $\mathrm{MEM}+\mathrm{AK}$ & MEM + PTZ & NIT & COL+MEM \\
\hline LOS (days) & 11 & 20 & 44 & 40 & 197 & 35 \\
\hline ND & 2 & 2 & 3 & 3 & 3 & 2 \\
\hline $\mathrm{Dl}$ & $\mathrm{PICU}$ & Surgery & PIDD & PIDD & PIDD & PIDD \\
\hline Evolution & Deceased & Deceased & Alive & Deceased & Alive & Alive \\
\hline
\end{tabular}

Dx diagnosis, AML-M2 acute myeloid leukemia M2, KTWS Klippel-Trenaunay-Weber syndrome, preB-ALL pre-B acute lymphoblastic leukemia, SSI surgical site infection, UTI urinary tract infection, PICU pediatric intensive care unit, MV mechanical ventilation, CVC central venous catheter, TPN total parenteral nutrition, $A B$ antibiotics, $3 G C$ third generation cephalosporins, Tx treatment, LOS length of in-hospital stay, COL colistin, MEM meropenem, AK amikacin, $P T Z$ piperacillin/tazobactam, NIT nitrofurantoin, ND number of clinical departments during hospitalization, DI Clinical department in which the isolate was obtained, PIDD Pediatric Infectious Diseases Department, ${ }^{\mathrm{a}}$ Days since admission to identification of the organism, ${ }^{\mathrm{b}}$ Isolation during meropenem treatment, ${ }^{\mathrm{C}}$ Escalating regimen

For C5, the isolation of NDM-1-producing E. coli belonging to clone ST131-O25b was obtained from a urinary tract infection (UTI). The ST131 clone is considered the most predominant pathogenic lineage of this species in extra-intestinal infections and is associated with resistance to fluoroquinolones and dissemination of the beta-lactamase CTX-M [29]. There are reports in Mexico of E. coli ST131-O25b causing UTI healthcareassociated and community acquired; these infections have been associated with CTX-M-15, but not NDM-1 [30]. NDM production by E. coli ST131 is rare but has been reported in clinical and environmental isolations in countries such as India, Vietnam, Serbia, Philippines [31] and U.S. [32, 33]. This is the first report of NDM-1producing E. coli ST131-O25b in Latin America.
Patient C6, who was infected with NDM-1-producing E. cloacae, received colistin for the treatment of fasciitis and presented a favorable therapeutic outcome. This isolate belonged to ST182, this clone has been described in our country recently involved in a hospital outbreak during 2014-2015 [34].

We identified an OXA-48-producing $K$. oxytoca isolate with susceptibility to third- and fourth-generation cephalosporins but resistance to carbapenems. This pattern is characteristic of isolates producing this enzyme. Moreover, the coexistence of ESBL in the same isolate may lead to the suspicion of another type of carbapenemase [35]. Using the CarbaNP test, we did not detect carbapenemase activity in this isolate, as was previously described; therefore, this test is not recommended for 
the detection of the OXA-type enzyme phenotype [36]. Five isolates of OXA-48-producing $K$. oxytoca were reported in 2010 in Turkey [37]; however, in contrast to the strain isolated from $\mathrm{C} 4$, these strains produce other ESBL, including SHV, TEM, CTX-M, and VEB. One OXA-48-producing $K$. oxytoca isolate was reported in Israel with susceptibility to ceftazidime, ceftriaxone, gentamicin and meropenem but resistance to imipenem and ertapenem [38].

The first report of OXA-48 enzymes produced by $E$. coli in our country was described in a cohort of patients at risk of being CPE fecal carriers, and three $K$. pneumoniae and $13 E$. coli isolates producing OXA-232 alone or in combination with other SHV and CTX-M-15 type beta-lactamases were obtained from this cohort [39]. Later, the same group reported that the most common carbapenemase in their hospital was OXA-232, mainly in $E$. coli and $K$. pneumoniae; infections by these microorganisms were associated with prior use of betalactams with beta-lactamase inhibitors and thirdgeneration cephalosporins [40]. The E. coli with OXA-232 isolate $(\mathrm{C} 1)$ belongs to ST2003 and additionally produces CTX-M-15. Although this ST has been associated with the production of other enzymes, such as KPC-2 and CTX-M-55 [41], there are no reports of OXA-232 production. The OXA-232 enzyme has also been found in E. coli ST457 and ST131 [25] and coexists in E. coli and K. pneumoniae isolates that produce other carbapenemases, such as NDM-1 [42, 43].

The two patients who suffered from CPE infections with OXA-type enzymes had leukemia as an underlying illness, the origin of these infections was abdominal, and both patients died (Table 3). The mortality reported by Enterobacteriaceae producing OXA-48-like enzymes reaches $50 \%$ [44]. This study represents the first report of OXA-48-producing $K$. oxytoca and OXA-232-producing E. coli in Mexican pediatric patients. Performing MLST for $K$. oxytoca was not possible.

The presence of other beta-lactamase enzymes was commonly reported in CPE, notably non-ESBL TEM and SHV, CTX-M-15, SHV-12, CMY and DHA subtypes, and sometimes other carbapenemases, such as VIM and IMP [16, 45-47]. We detected non-ESBL enzymes (TEM-1 and SHV-1) as well as ESBL (CTXM-15 and SHV-12) in four isolates, but none produced enzymes of the CMY and DHA types or the other CTX-M subtypes. CTX-M-15 has also been found in CPE that produce NMD-1 [27]. However, CTX-M-15 and SHV-12 are the most commonly detected ESBL in other third-level hospitals in Mexico [30]. In two isolates, E. coli and E. cloacae with NDM-1 (case 5 and 6, respectively) we found CTX$\mathrm{M}-15$, but we could not phenotypically detect the production of ESBL, according to the literature this can be explained because the NDM type enzymes are not inhibited by clavulanic acid, which can intervene in the interpretation of the ESBL test, when NDM and CTX-M-15 co-exist in the same isolate [48]. A variety of risk factors have been considered in the acquisition of $\mathrm{CPE}$, such as prior, recurrent, or prolonged hospitalization, the use of antimicrobials, immunosuppression, the presence of central venous catheters, intensive care unit (ICU) admission and recent surgery [49]. The majority of patients in this series had these risk factors.

The mortality in this study was high, because half patients died. This finding is similar to other reports in the literature; the mortality of patients with CPE infection reached $44 \%$ [2]. In our series, all patients with documented CPE with bloodstream infection died. Mortality can reach $85 \%$ in cases of bloodstream infection [3]. All cases were controlled, and no secondary cases appeared. The emergence of these CPE isolates was an institutional alarm because all cases were healthcare-associated infections; because we do not have a surveillance program for the detection of CPE carriers in the INP. Four patients among six had recurrent or prolonged hospitalization in our hospital, considered a risk factor. However, two cases (C2 and C6) were patients who came from other hospitals and in whom an infection was detected earlier (8 and 9 days, respectively). Therefore, these patients may have been colonized prior to admission at our institution. The role of CPE colonization at the intestinal level is well documented and allows cross-transmission and dissemination in healthcare institutions $[49,50]$. CPE as the cause of outbreaks is a growing problem that is reported at a global level. Therefore, establishing screening programs for the early identification of these pathogens through rectal swabs of these patients is important [50], as is the implementation of prevention and control measures to avoid dissemination of these pathogens $[49,50]$.

\section{Conclusions}

This study reports the clinical, epidemiological and molecular characteristics of seven consecutive CPE cases. We report the finding of Enterobacteriaceae isolates producing carbapenemases not previously detected in Mexican pediatric patients. Finally, this is the first report of an NDM-1-producing E. coli ST131-O25b clone in Latin America.

The monitoring, surveillance, and control of CPE should be reinforced due to the ease of resistance cross-transmission among these pathogens, the possibility of dissemination, and the limited therapeutic possibilities. 


\section{Abbreviations}

3GC: third generation cephalosporins; AB: antibiotics; AK: amikacin; AMLM2: acute myeloid leukemia M2; AMP/SULB: ampicillin/sulbactam; AZT: aztreonam; BLAST: Basic Local Alignment Serach Tool; CAZ: ceftazidime; CBP: carbapenemases; CFZ: cefazolin; CIP: ciprofloxacin; CLSI: Clinical Laboratory Standards Institute; CMY-1: cephamycin AmpC beta-lactamase; COL: colistin; CPE: Carbapenemase-producing Enterobacteriaceae; CRO: ceftriaxone; CTX: cefotaxime; CTX-M: Cefotaximase-München; CVC: central venous catheter; CXM: cefuroxime; DHA: Dhahran Hospital, Saudi Arabia AmpC beta-lactamase; Dl: Clinical department in which the isolate was obtained; Dx: diagnosis; ERT: ertapenem; ESBL: extended spectrum beta-lactamases; FEP: cefepime; FOX: cefoxitin; GE: gentamicin; ICU: intensive care unit; IMP: imipenem; IMP: imipenemase; INP: National Institute of Pediatrics; IR: intrinsic resistance; KPC-2: Klebsiella pneumoniae carbapenemase; KTWS: Klippel-Trenaunay-Weber syndrome; LAT: latamoxef AmpC beta-lactamase; LEV: levofloxacin; LOS: length of in-hospital stay; MEM: meropenem; MIC: minimum inhibitory concentration; MLST: Multilocus Sequence Typing; MV: mechanical ventilation; ND: not determined; ND: number of clinical departments during hospitalization; NDM-1: New Delhi metallo- $\beta$-lactamase; NIT: nitrofurantoin; OXA-232: oxacillinase-232; OXA-48: oxacillinase-48; PICU: pediatric intensive care unit; PIDD: Pediatric Infectious Diseases Department; preB-ALL: pre-B acute lymphoblastic leukemia; PTZ: piperacillin/tazobactam; SHV: Sulfhydryl variable betalactamaase; SSI: surgical site infection; ST: sequence types; SXT: trimethoprim sulfamethoxazole; TE: tetracycline; TEM: Temoneira beta-lactamase; TOB: tobramycin; TPN: total parenteral nutrition; Tx: treatment; UTI: urinary tract infection; VEB: Vietnamese extended-spectrum beta-lactamases; VIM: Verona integron-encoded metallo- $\beta$-lactamase

\section{Acknowledgements}

We thank to MsC Silvestre Ortega Peña for support in microbiological methods.

\section{Funding}

We appreciate the support provided by the National Council for Science and Technology (Consejo Nacional de Ciencia y Tecnología) through the Health Sector Fund (Fondo Sectorial de Salud FOSSIS) in project 2012-1-181041 and the Federal Budget Research Funds (Fondos de Presupuesto Federal para Investigación) 2016 of the INP. They had none role in the design of the study and collection, analysis, and interpretation of data and in writing the manuscript.

\section{Availability of data and materials}

All the data supporting our findings is contained within the manuscript.

\section{Authors' contributions}

AAA, JMV and ADC designed the study; AAA and JMV performed the experiments; $A D C$ and EAG collected the epidemiological data; AAA, JMV and $P A B$ collected the microbiological data; $A A A$ and $A D C$ analyzed the data; AAA and ADC wrote the manuscript. All authors read and approved the final manuscript.

\section{Ethics approval and consent to participate}

This descriptive study was approved by the ethics and research committees of the INP (IRB:00008064, reference number of protocol 066/2013). In this study, informed consent was not necessary because the isolates included in the study were obtained as part of standard care. Patient identity and all the personal information were confidential. The data used in this study was de-identified.

\section{Competing interests}

The authors declare that they have no competing interests.

\section{Publisher's Note}

Springer Nature remains neutral with regard to jurisdictional claims in published maps and institutional affiliations.

\section{Author details}

${ }^{1}$ Molecular Microbiology Laboratory, Instituto Nacional de Pediatría, Insurgentes Sur 3700-C, Insurgentes Cuicuilco, ZC, 04530 Coyoacán Mexico City, Mexico. ${ }^{2}$ Pediatric Infectious Disease Department, Instituto Nacional de Pediatria, Mexico City, Mexico. ${ }^{3}$ Clinical Bacteriology Laboratory, Instituto Nacional de Pediatria, Mexico City, Mexico.
Received: 21 July 2017 Accepted: 15 March 2018

Published online: 19 April 2018

\section{References}

1. Perez F, Chakhtoura NGE, Papp-Wallace KM, Wilson BM, Bonomo RA. Treatment options for infections caused by carbapenem-resistant Enterobacteriaceae: can we apply "precision medicine" to antimicrobial chemotherapy? Expert Opin Pharmacother. 2016;17:761-81.

2. Falagas ME, Tansarli GS, Karageorgopoulos DE, Vardakas KZ. Deaths attributable to carbapenem-resistant Enterobacteriaceae infections. Emerg Infect Dis. 2014;20:1170-5.

3. Villegas MV, Pallares CJ, Escandon-Vargas K, Hernandez-Gomez C, Correa A, Alvarez C, et al. Characterization and clinical impact of bloodstream infection caused by Carbapenemase-producing Enterobacteriaceae in seven Latin American countries. PLoS One. 2016;11:e0154092.

4. Potter RF, D'Souza AW, Dantas G. The rapid spread of carbapenem-resistant Enterobacteriaceae. Drug Resist Updat. 2016;29:30-46.

5. Latania KL, John PR, Sumanth G, Robert AW, Ramanan L. Carbapenemresistant Enterobacteriaceae in children, United States, 1999-2012. Emerg Infect Dis. 2015;21:2014-21.

6. Sader HS, Castanheira M, Flamm RK, Mendes RE, Farrell DJ, Jones RN. Tigecycline activity tested against carbapenem-resistant Enterobacteriaceae from 18 European nations: results from the SENTRY surveillance program (2010-2013). Diagn Microbiol Infect Dis. 2015;83:183-6.

7. Sader HS, Castanheira M, Farrell DJ, Flamm RK, Mendes RE, Jones RN. Tigecycline antimicrobial activity tested against clinical bacteria from Latin American medical centres: results from SENTRY antimicrobial surveillance program (2011-2014). Int J Antimicrob Agents. 2016:48:144-50.

8. Centers of Diseases Control and Prevention. CDC/NHSN surveillance definitions for specific types of infections. http://www.cdc.gov/nhsn/pdfs/ pscmanual/17pscnosinfdef_current.pdf. Accessed 05 June 2017.

9. Clinical Laboratory Standards Institute. Performance standards for antimicrobial susceptibility testing; 26th informational supplement MI00-S25. Wayne, Pennsylvania (PA): CLSI; 2016.

10. Dallenne C, da Costa A, Decre D, Favier C, Arlet G. Development of a set of multiplex PCR assays for the detection of genes encoding important beta-lactamases in Enterobacteriaceae. J Antimicrob Chemother. 2010;65:490-5.

11. Nordmann P, Poirel L, Carrer A, Toleman MA, Walsh TR. How to detect NDM-1 producers. J Clin Microbiol. 2011;49:718-21.

12. Brink AJ, Coetzee J, Corcoran C, Clay CG, Hari-Makkan D, Jacobson RK, et al. Emergence of OXA-48 and OXA-181 Carbapenemases among Enterobacteriaceae in South Africa and evidence of in vivo selection of colistin resistance as a consequence of selective decontamination of the gastrointestinal tract. J Clin Microbiol. 2013;51:369-72.

13. Wirth T, Falush D, Lan R, Colles F, Mensa P, Wieler LH, et al. Sex and virulence in Escherichia coli: an evolutionary perspective. Mol Microbiol. 2006;60:1136-51.

14. Diancourt L, Passet V, Verhoef J, Grimont PA, Brisse S. Multilocus sequence typing of Klebsiella pneumoniae nosocomial isolates. J Clin Microbiol. 2005;43:4178-82.

15. Miyoshi-Akiyama T, Hayakawa K, Ohmagari N, Shimojima M, Kirikae T. Multilocus sequence typing (MLST) for characterization of Enterobacter cloacae. PLoS One. 2013;8:e66358.

16. Clermont $\mathrm{O}$, Lavollay M, Vimont S, Deschamps C, Forestier C, Branger C, et al. The CTX-M-15-producing Escherichia coli diffusing clone belongs to a highly virulent B2 phylogenetic subgroup. J Antimicrob Chemother. 2008:61:1024-8.

17. Kazmierczak KM, Biedenbach DJ, Hackel M, Rabine S, de Jonge BL, Bouchillon SK, et al. Global dissemination of blaKPC into bacterial species beyond Klebsiella pneumoniae and in vitro susceptibility to ceftazidimeavibactam and aztreonam-avibactam. Antimicrob Agents Chemother. 2016;60:4490-500.

18. Morfin-Otero R, Rodriguez-Noriega E, Deshpande LM, Sader HS, Castanheira M. Dissemination of a bla(VIM-2)-carrying integron among Enterobacteriaceae species in Mexico: report from the SENTRY antimicrobial surveillance program. Microb Drug Resist. 2009;15:33-5.

19. Labrador I, Araque M. First description of KPC-2-producing Klebsiella oxytoca isolated from a pediatric patient with nosocomial pneumonia in Venezuela. Case Rep Infect Dis. 2014;2014:434987. 
20. Pang F, Jia XQ, Song ZZ, Li YH, Wang B, Zhao QG, et al. Characteristics and management of Enterobacteriaceae harboring IMP-4 or IMP-8 carbapenemase in a tertiary hospital. Afr Health Sci. 2016;16:153-61.

21. Caltagirone M, Bitar I, Piazza A, Spalla M, Nucleo E, Navarra A, et al. Detection of an InCA/C plasmid encoding VIM-4 and CMY-4 $\beta$-lactamases in Klebsiella oxytoca and Citrobacter koseri from an inpatient in a cardiac rehabilitation unit. New Microbiol. 2015;38:387-92.

22. Rodriguez-Zulueta P, Silva-Sanchez J, Barrios H, Reyes-Mar J, Velez-Perez F, Arroyo-Escalante $\mathrm{S}$, et al. First outbreak of KPC-3-producing Klebsiella pneumoniae (ST258) clinical isolates in a Mexican medical center. Antimicrob Agents Chemother. 2013;57(8):4086.

23. Garza-Ramos U, Moreno-Dominguez S, Hernandez-Castro R, Silva-Sanchez J, Barrios H, Reyna-Flores F, et al. Identification and characterization of imipenem-resistant Klebsiella pneumoniae and susceptible Klebsiella variicola isolates obtained from the same patient. Microb Drug Resist. 2016;22:179-84.

24. Guo S, Wakeham D, Brouwers HJ, Cobbold RN, Abraham S, Mollinger JL, et al. Human-associated fluoroquinolone-resistant Escherichia coli clonal lineages, including ST354, isolated from canine feces and extraintestinal infections in Australia. Microbes Infect. 2015;17:266-74.

25. Jeong SH, Lee KM, Lee J, Bae IK, Kim JS, Kim HS, et al. Clonal and horizontal spread of the blaOXA-232 gene among Enterobacteriaceae in a Korean hospital. Diagn Microbiol Infect Dis. 2015;82:70-2.

26. Barrios H, Garza-Ramos U, Reyna-Flores F, Sanchez-Perez A, Rojas-Moreno T, Garza-Gonzalez E, et al. Isolation of carbapenem-resistant NDM-1-positive Providencia rettgeri in Mexico. J Antimicrob Chemother. 2013;68:1934-6.

27. Torres-Gonzalez P, Valle MBD, Tovar-Calderon E, Leal-Vega F, HernandezCruz A, Martinez-Gamboa A, et al. Outbreak caused by Enterobacteriaceae harboring NDM-1 metallo-beta-lactamase carried in an IncFll plasmid in a tertiary care hospital in Mexico city. Antimicrob Agents Chemother. 2015;59:7080-3.

28. Barrios H, Silva-Sanchez J, Reyna-Flores F, Sanchez-Perez A, Sanchez-Francia D, Aguirre-Torres JA, et al. Detection of a NDM-1-producing Klebsiella pneumoniae (ST22) clinical isolate at a pediatric hospital in Mexico. Pediatr Infect Dis J. 2014;33:335

29. Stoesser N, Sheppard AE, Pankhurst L, de Maio N, Moore CE, Sebra R, et al. Evolutionary history of the global emergence of the Escherichia coli epidemic clone ST131. MBio. 2016;7:e02162.

30. Miranda-Romero AL, Silva-Sanchez J, Garza-Ramos U, Barrios H, SanchezPerez A, Reyna-Flores F. Molecular characterization of ESBL-producing Escherichia coli isolates from hospital- and community-acquired infections in NW Mexico. Diagn Microbiol Infect Dis. 2017;87:49-52.

31. Peirano G, Bradford PA, Kazmierczak KM, Badal RE, Hackel M, Hoban DJ, et al. Global incidence of carbapenemase-producing Escherichia coli ST131. Emerg Infect Dis. 2014;20:1928-31.

32. Peirano G, Schreckenberger PC, Pitout JD. Characteristics of NDM-1producing Escherichia coli isolates that belong to the successful and virulent clone ST131. Antimicrob Agents Chemother. 2011;55:2986-8.

33. Kutumbaka KK, Han S, Mategko J, Nadala C, Buser GL, Cassidy MP, et al. Draft genome sequence of Bla(NDM-1)-positive Escherichia coli O25b-ST131 clone isolated from an environmental sample. Genome Announc. 2014;2:e00462-14.

34. Bocanegra-lbarias P, Garza-González E, Morfín-Otero R, Barrios H, VillarrealTreviño L, Rodríguez-Noriega $\mathrm{E}$, et al. Molecular and microbiological report of a hospital outbreak of NDM-1-carrying Enterobacteriaceae in Mexico. PLoS One. 2017;12:e0179651.

35. Bakthavatchalam YD, Anandan S, Veeraraghavan B. Laboratory detection and clinical implication of oxacillinase-48 like carbapenemase: the hidden threat. J Glob Infect Dis. 2016;8:41-50.

36. Österblad M, Hakanen AJ, Jalava J. Evaluation of the Carba NP test for carbapenemase detection. Antimicrob Agents Chemother. 2014;58:7553-6.

37. Nazik H, Aydin S, Albayrak R, Bilgi EA, Yildiz I, Kuvat N, et al. Detection and spread of oxa-48-producing Klebsiella oxytoca isolates in Istanbul, Turkey. Southeast Asian J Trop Med Public Health. 2014;45:123-9.

38. Adler A, Shklyar M, Schwaber MJ, Navon-Venezia S, Dhaher Y, Edgar R, et al. Introduction of OXA-48-producing Enterobacteriaceae to Israeli hospitals by medical tourism. J Antimicrob Chemother. 2011;66:2763-6.

39. Torres-Gonzalez P, Cervera-Hernandez ME, Niembro-Ortega MD, LealVega F, Cruz-Hervert LP, Garcia-Garcia L, et al. Factors associated to prevalence and incidence of carbapenem-resistant Enterobacteriaceae fecal carriage: a cohort study in a Mexican tertiary care hospital. PLoS One. 2015;10:e0139883.
40. Torres-Gonzalez P, Ortiz-Brizuela E, Cervera-Hernandez ME, Valle MBD, Martinez-Gamboa A, Sifuentes-Osornio J, et al. Associated factors and outcomes for OXA-232 Carbapenem-resistant Enterobacteriaceae infections in a tertiary care Centre in Mexico City: a case-control-control study. Diagn Microbiol Infect Dis. 2016;86:243-8.

41. Cai JC, Zhang R, Hu YY, Zhou HW, Chen GX. Emergence of Escherichia coli sequence type 131 isolates producing KPC-2 carbapenemase in China. Antimicrob Agents Chemother. 2014;58:1146-52.

42. Doi Y, O'Hara JA, Lando JF, Querry AM, Townsend BM, Pasculle AW, et al. Co-production of NDM-1 and OXA-232 by Klebsiella pneumoniae. Emerg Infect Dis. 2014;20:163-5.

43. Both A, Huang J, Kaase M, Hezel J, Wertheimer D, Fenner I, et al. First report of Escherichia coli co-producing NDM-1 and OXA-232. Diagn Microbiol Infect Dis. 2016;86:437-8.

44. Lowman W, Schleicher G. Antimicrobial treatment and outcomes of critically ill patients with OXA-48like carbapenemase-producing Enterobacteriaceae infections. Diagn Microbiol Infect Dis. 2015;81:138-40.

45. Pannaraj PS, Bard JD, Cerini C, Weissman SJ. Pediatric carbapenem-resistant Enterobacteriaceae in Los Angeles, California, a high-prevalence region in the United States. Pediatr Infect Dis J. 2015;34:11-6.

46. Thoms-Rodriguez CA, Mazzulli T, Christian N, Willey BM, Boyd DA, Mataseje LF, et al. New Delhi metallo-beta-lactamase in Jamaica. J Infect Dev Ctries. 2016;10:183-7.

47. Lee CR, Lee JH, Park KS, Kim YB, Jeong BC, Lee SH. Global dissemination of carbapenemase-producing Klebsiella pneumoniae: epidemiology, genetic context, treatment options, and detection methods. Front Microbiol. 2016;7:895.

48. Carbapenemases BK. Partners in crime. J Glob Antimicrob Resist. 2013;1:7-16.

49. Carmeli Y, Akova M, Cornaglia G, Daikos GL, Garau J, Harbarth S, et al. Controlling the spread of carbapenemase-producing gram-negatives: therapeutic approach and infection control. Clin Microbiol Infect. 2010;16:102-11.

50. Viau R, Frank KM, Jacobs MR, Wilson B, Kaye K, Donskey CJ, et al. Intestinal carriage of carbapenemase-producing organisms: current status of surveillance methods. Clin Microbiol Rev. 2016;29:1-27.

\section{Submit your next manuscript to BioMed Central and we will help you at every step:}

- We accept pre-submission inquiries

- Our selector tool helps you to find the most relevant journal

- We provide round the clock customer support

- Convenient online submission

- Thorough peer review

- Inclusion in PubMed and all major indexing services

- Maximum visibility for your research

Submit your manuscript at www.biomedcentral.com/submit
Biomed Central 